\title{
ESQ Way 165: Alternatif Metode Pengembangan Kecerdasan Emosi dan Spiritual Anak
}

\section{ESQ Way 165: An Alternative Methods to Developing Emotional dan Spiritual Intelligence of Children}

\author{
Ferdian Utama ${ }^{1}$ \\ ${ }^{1}$ IAIM NU Metro, Lampung, Indonesia \\ ${ }^{1}$ Email: ferdianutama@gmail.com
}

\begin{abstract}
Abstrak
Kecerdasan emosi dan kecerdasaran spritual pada anak perlu dikembangkan sejak usia dini. Hal tersebut disebabkan oleh munculnya berbagai permasalahan pada saat anak telah menginjak remaja atau aqil baliqh ketika kecerdasan emosi dan spiritual anak tidak dikembangkan dengan tepat. Kecerdasan emosi merupakan kemampuan dalam mengelola segala dorongan perasaan yang ada pada dirinya, sedangkan kecerdasan spiritual adalah kemampua seorang individu untuk mengembangkan diri secara utuh dengan menerapkan nilai-nilai positif dalam memaknai dan menyelesaikan permasalahan kehidupan. Permasalahan yang sering muncul ketika anak memasuki remaja antara lain nongkrong dan bagadang tanpa tujuan yang jelas dan manfaat, mengonsumsi narkoba, bunuh diri, bolos sekolah, seks bebas, berperilaku impulsif, dan sebagainya. Permasalahan-permasalahan tersebut tidak terlepas dari pengalaman emosi dan pengasuhan sejak usia dini. Penelitian ini menggunakan pendekatan kualitatif dengan metode content analysis. Buku Ari Ginanjar yang berjudul "Rahasia Suskes Membangkitkan ESQ Power" karya Ary Ginajar Agustian menjadi sumber data utama penelitian ini. Melalui hasil analisis data ditemukan bahwa tahapan pembangunan ESQ melalui metode ESQ Way 165 antara lain: penjernihan emosi, pembangunan mental, ketangguhan pribadi, ketangguhan sosial. Metode ESQ Way 165 direkomendasikan bagi para orangtua dan guru sebagai alternatif dalam mengembangkan kecerdasan emosi dan spiritual anak. Harapannya, dengan dikembangkannya kecerdasan-kecerdasan tersebut sejak dini dapat membantu anak-anak tumbuh menjadi manusia sempurna, yaitu sebagai pribadi yang mampu memaknai permasalahan dan menyelesaikannya secara positif melalui pengelolaan dorongan perasaan yang baik sesuai ajaran Islam. Dengan demikian, mereka akan memiliki keterampilan dalam berpikir, memilih, dan memutuskan segala sesuatu dengan tepat dan berdasarkan nilainilai Ikhsan, Iman, dan Islam.
\end{abstract}

Kata kunci: kecedasaran, emosi, spiritual, ESQ Way 165, anak

\begin{abstract}
Emotional intelligence and spiritual intelligence in children need to be developed start from an early age. This is caused by the emergence of various problems when the child has stepped on a teenager when the child's emotional and spiritual intelligence is not developed properly. Emotional intelligence is the ability to manage all the impulses that feel on him, while spiritual intelligence is the ability of an individual to develop themselves as a whole by applying positive values in meaning and solve the problems of life. The problems that often arise when the child enters adolescence, among others hanging out and going untill overnight without any goals and benefits, taking drugs, suicide, truant of school, free sex, behave impulsively, and etc. These problems can not be separated from emotional experiences and parenting patterns from an early age. This research uses qualitative approach with content analysis method. Ari Ginanjar's book entitled "The Secret of Suskes Generating ESQ Power" by Ary Ginajar Agustian becomes the main data source of this research. Through the results of data analysis found that the stages of ESQ development through ESQ Way 165 methods include: emotional cleansing, mental development, personal toughness, social toughness. The ESQ Way 165 method is recommended for parents and teachers as an alternative in developing children's emotional and spiritual intelligence. The hope, with the development of these intelligences from an early age can help children grow up to be perfect human, that is as a person who is able to interpret the problem and solve it positively through the management of a good feeling encouragement in accordance with Islamic teachings. Thus, they will have the skills to think, choose, and decide everything appropriately and based on the values of Ikhsan, Faith and Islam.
\end{abstract}

Keywords: intelligence, emotion, spiritulality, ESQ Way 165, children

Submitted: 12 Maret 2018, Accepted: 1 April 2018, Published:2 April 2018 


\section{PENDAHULUAN}

Saat ini banyak fenomena yang muncul dari potret kenakalan remaja. Dimulai dari permasalahan penyimpangan perilaku biasa hingga mengarah pada perilaku kriminal. Sebagaimana perilaku pembacokan yang telah dilakukan oleh 3 pelajar SMPN 4 Cikarang Barat akhir tahun 2017 yang lalu (Sindonews, 2017), sehingga tindakan mereka dapat dikategorikan pada perilaku kriminal. Perilaku kriminal lainnya oleh remaja di Jawa Tengah dan DI. Yogyakarta yang belum tuntas adalah klithih (Liputan6.com, 2017).

Permasalahan berikutnya antara lain nongkrong dan bagadang tanpa tujuan yang jelas dan manfaat, mengonsumsi narkoba, bunuh diri, bolos sekolah, seks bebas, berperilaku impulsif, dan sebagainya. Perilaku-perilaku kenakalan remaja tidak terlepas dari pengalaman emosi serta pola pengasuhan mereka sejak usia kanak-kanak (Nindya \& Margaretha, 2012; Setyowati, 2013; Suryani, 2014).

Permasalahan-permasalahan tersebut, di samping harus mendapatkan solusi bagi mereka yang telah berada pada usia remaja tetapi juga perlu ada upaya pencegahan terjadinya kembali kenakalan-kenalakan remaja di masa mendatang dimulai sejak usia dini. Upaya pencegahan tersebut dapat dilakukan dimulai dengan mengembangkan kecerdasan emosi dan kecerdasasan spiritual anak usia dini.

Kecerdasan emosi merupakan kemampuan yang dimiliki seeorang untuk mengendalikan dan mengelola segala dorongan perasaan dari dalam dirinya. Emosi yang stabil menjadikan perilaku seseorang menjadi baik, sehingga tujuannya dapat tercapai. Dalam memunculkan emosi yang stabil tersebut, melalui beberapa proses dan tahapan. Tidak semata-mata lahir dari dalam dirinya (Goleman, 2000).

Adapun macam-macam kecerdasan emosional meliputi, mengidentifikasi perasaan, mengungkapkan perasaan, menilai intensitas perasaan, mengelola perasaan, menunda pemuasan, mengendalikan dorongan hati, mengurangi stres, dan mengontrol tindakan.
Kecerdasan-kecerdasan emosi tersebut dapat dipengaruhi oleh proses komunikasi dan proses pengasuhan yang dialami oleh anak (Arfiani, 2014; Suryani, 2014). Dengan demikian, kecerdasan emosi dapat dibangun dari sejak usia kanak-anak.

Kecerdasan spiritual adalah sesuatu yang memberikan makna dan nilai dari apa yang telah dilakukan. Makna dan nilai diperoleh berdasarkan keyakinan yang diimaninya. Biasanya untuk memiliki keimanan tersebut bersumber dari doktrin keyakinan seseorang kepada sesuatu yang dianggap benar dan menjadi pedoman hidupnya. Kemampuan spiritual biasanya ditandai dengan kemampuan seseorang dalam mengendalikan hawa nafsunya karena tidak sesuai dengan nilainilai yang ada dalam keyakinannya.

Pendapat lain menyebutkan bahwa kecerdasan spiritual adalah landasan dari setiap perbuatan dan tingkah laku seseorang berdasarkan keimanan yang dimiliki. Dalam hal ini dikatakan bahwa seseorang harus beriman kepada Allah, karena segala macam perbuatannya berdasarkan karena Allah (Ginanjar, 2007). Pada prinsipnya, dengan dimilikinya kecerdasan spiritual maka seorang individu akan senantiasa melakukan tindakan dan pengambilan keputusan dalam hidupnya didasarkan pada nilai-nilai yang diimaninya. Di lain pihak, kecerdasan spiritual seorang siswa dan mahasiswa juga terbukti dapat mempengaruhi prestasi belajarnya (Tikollah, Triyuwono, \& Ludigdo, 2006; Trihandini, 2005).

Berbagai upaya dalam mengembangkan kecerdasan emosi telah banyak dilakukan, misalnya seperti penerapan metode hypnoteaching di Satuan PAUD yang diberikan untuk anak usia dini (Luthfiyani, Herawati, \& Rohayati, 2016; Rohmadheny, 2013). Mengembangkan emosi juga dapat dilakukan melalui permainan dan keteladanan (Hariastuti \& Saman, 2007). Salah satu konsep lain yang dapat diterapkan sebagai alternatif metode dalam mengembangkan kecerdasaran emosi dan spiritual anak adalah melalui metode ESQ Way 165 suatu metode yang berdasar pada ajaran Islam. Melalui penelitian ini, 
peneliti mencoba menggali, menganalisis, dan mendeksripsikan perspektif Ary Ginanjar Agustian dalam merumuskan metode ESQ Way 165 melalui teks dalam bukunya.

\section{METODE PENELITIAN}

Penelitian ini menggunakan pendekatan kualitatif dengan metode content analysis. Buku Ari Ginanjar yang berjudul "Rahasia Suskes Membangkitkan ESQ Power" karya Ary Ginajar Agustian menjadi sumber data primer penelitian ini, sedangkan sumber data sekundernya adalah teori dan hasil penelitian lain sebagai data penunjang. Data yang diperoleh melalui sumber primer diklasifikaskan sesuai tema yang menjadi fokus penelitian untuk dilakukan analisis dan dikomparasi dengan sumber data sekunder, kemudian diinterpretasikan dan diambil kesimpulan.

\section{HASIL DAN PEMBAHASAN}

\section{A. Konsep ESQ Way 165}

Berdasarkan hasil analisis data, ditemukan konsep yang mendasari pemikiran Ary Ginanjar Agustian tentang Emotional Spiritual Quotient (ESQ) adalah nilai-nilai ikhsan, rukun iman dan rukun Islam. Di samping sebagai petunjuk ibadah bagi umat Islam, pokok pikiran dalam ketiga nilai tersebut juga memberikan bimbingan untuk mengenali dan memahami perasaan kita sendiri dan perasaan orang lain, memotivasi diri, dan mengelola emosi dalam berhubungan dengan orang lain. Suatu metode membangun emotional quotient (EQ) yang didasari dengan hubungan antara manusia dengan Tuhannya (spiritual quotient).

Meskipun kecerdasan emosi dan spiritual berbeda, tetapi keduanya memiliki muatan yang sama-sama penting untuk dapat bersinergi antara satu dengan yang lain. Penggabungan dari kecerdasan emosi dan kecerdasan spiritual dinamakan emotional spiritual quotient (ESQ). Sebuah penggabungan gagasan kedua energi yang berguna untuk menyusun metode yang lebih dapat diandalkan dalam menemukan pengetahuan yang benar dan hakiki. Ary
Ginanjar Agustian mendefinisikan Emotional Spiritual Quotient (ESQ) sebagai sebuah kecerdasan yang meliputi emosi dan spiritual dengan konsep universal yang mampu menghantarkan pada predikat memuaskan bagi dirinya dan orang lain, serta dapat menghambat segala hal yang kontradiktif terhadap kemajuan umat manusia.

Secara sederhana Ary Ginanjar Agustian menggambarkan konvergensi bentuk kecerdasan tersebut sebagai berikut.
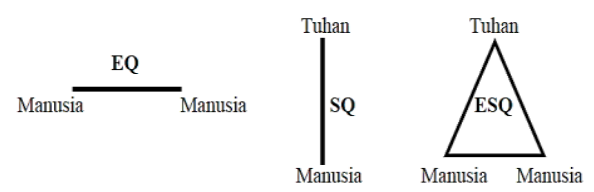

Gambar 1. Konvergensi Kecerdasan (Ginanjar, 2007)

B. Tahap Pembangunan ESQ dengan metode ESQ Way 165

Berdasarkan pendapat Ary Ginanjar Agustian, emotional spiritual quotient (ESQ) adalah kecerdasan yang bertujuan untuk membangun kecerdasan emosi (EQ) dan kecerdasan spiritual (SQ) secara terintegrasi dan berkesinambungan sesuai dengan ajaran Islam atau yang lebih dikenal dengan The ESQ Way 165. Metode ESQ Way 165 menimbulkan kekuatan keimanan dari dalam diri dan hati seseorang. Gambaran pemetaan dari nilainilai ihsan, rukun iman dan rukun Islam sebagai berikut.

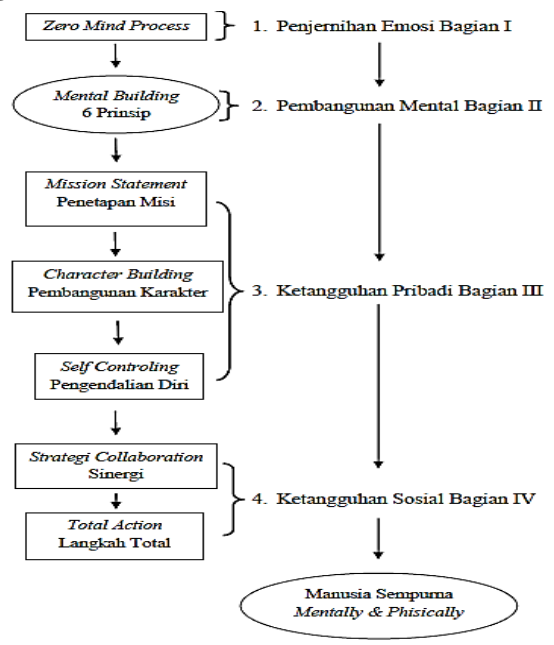

Gambar 2. Pemetaan Ikhsan, Iman, dan Islam 
Gambar di atas menjelaskan tentang pemetaan nilai-nilai yang menjadi dasar filosofis metode ESW Way 165. Nilai-nilai yang menjadi dasar metode ESQ Way 165 tersebut antara lain nilai-nilai ihsan, rukun iman dan rukun Islam. Tahapan penerapan ESQ Way 165 antara lain: penjernihan emosi, pembangunan mental, ketangguhan pribadi, dan ketangguhan sosial.

Penjernihan Emosi (Zero Mind Proccess) adalah tahapan pertama dalam pembangunan emotional spiritual quotient (ESQ). Zero Mind Proccess yang sering dikenal dengan kejernihan hati, mencoba mendefinisikan beberapa hal yang menjadi sumber kehancuran manusia dengan tujuh belenggu yang terdapat dalam diri manusia atau upaya untuk mengenali dan menghapus apa yang menutupi potensi dalam hati, sehingga spiritual power akan muncul. Dari sinilah awal kecerdasan spiritual mulai terbangun. Manusia di sini memiliki nilai yang satu bersifat universal dan ihsan (indah).

Pembangunan mental (Mental Building) adalah tahapan kedua. Pada tahnapan ini, kecerdasan emosi dibangun melalui enam prinsip yang didasarkan atas rukun iman, yaitu membangun prinsip bintang sebagai pegangan hidup, memiliki prinsip malaikat sehingga dapat dipercaya oleh orang lain, memiliki prinsip kepemimpinan, menyadari pentingnya prinsip pembelajaran, mempunyai prinsip masa depan, dan mempunyai prinsip keteraturan.

Ketangguhan Pribadi (Personal Strength) merupakan tahap ketiga. Ketangguhan pribadi adalah ketika seseorang berada pada posisi telah memiliki pegangan/prinsip hidup yang kokoh dan jelas. Sehingga seseorang yang memiliki ketangguhan pribadi tidak akan mudah terpengaruh oleh lingkungan yang terus berubah dengan cepat.

\section{Ketangguhan Sosial (Social} Strength) merupakan tahap keempat. Ketangguhan sosial adalah penyikapan diri terhadap lingkungan dan masyarakat sekitar. Sikap peduli terhadap sesama dan peduli terhadap lingkungan alam sekitar.

\section{Pengembangan Kecerdasan Emosi dan Spiritual Anak melalui metode ESQ Way 165}

Berdasarkan karakteristik anak usia dini dan sifat-sifat agama pada anak diantaranya adalah Unreflectife, Egosentris, Anthropomorphis, ritualis, imitatif, dan rasa heran (Komarudin, 2003). Maka penanaman ESQ terhadap anak bisa diterapkan secara bertahap. Semua perilaku yang dilakukan oleh anak berdasarkan sikap pembiasaan kesehariaanya. Kemudian seiring dengan perilakunya, maka harus berlandaskan keyakinan yang harus diimani, dalam hal ini adalah beriman kepada Allah S.W.T.

Ketangguhan pribadi atau Personal Strength dalam buku Ary Ginanjar disebutkan langkah-langkah yang harus dilakukan, antara lain: Mission Statement, Character Building, dan Self Controling.

Pada tahap mission statement, syahadat merupakan suatu pembangunan kesadaran akan satu keyakinan. Syahadat akan membangun sebuah keyakinan dalam berusaha dan menciptakan suatu daya pendorong dalam upaya mencapai tujuan, serta akan membangkitkan keberanian dan optimisme, sekaligus menciptakan ketenangan batin dalam menjalankan misi hidup. Maka penerapan yang dilakukan terhadap anak adalah mengajarkan kalimat syahadat kepada anak dan melakukan sikap pembiasaan islami terhadap anak, sebagai bentuk penanaman aqidah keyakinan anak kepada Allah. Banayak hal yang mendorong sikap dan pembiasaan tersebut, diantaranya selalu bersyahadat, mengucap sholawat, menyebutkan asmaul husna, dan membaca alqur'an sebelum pembelajaran dimulai.

Berikutnya pada tahap Character Building, shalat menjadi suatu metode relaksasi untuk menjaga kesadaran diri agar tetap memiliki cara berpikir yang jernih. Sholat adalah sebuah metode yang 
dapat meningkatkan kecerdasan emosi dan spiritual secara terus menerus. Sholat adalah teknik pembentukan pengalaman yang membangun suatu paradigma positif. Nilai-nilai dalam shalat inilah yang akan menjadi jawaban dari setiap masalah yang timbul dalam kehidupan. Shalat dapat ditanamkan pada diri anak, namun dalam hal ini shalat dilakukan dengan pembiasaan sehari-hari terhadap anak. Dengan melakukan pembiasaan shalat, maka anak akan tau dan terbiasa tentang pelaksanaan shalat dan fungsi shalat.

Kemudian pada tahap Self Controling, senjata yang ampuh dalam memelihara diri adalah puasa. Puasa adalah suatu metode pelatihan untuk pengendalian diri. Puasa bertujuan untuk meraih suatu kemerdekaan sejati, dan pembebasan dari belenggu yang tak terkendali. Penanaman terhadap anak dapat dilakukan dengan cara peduli terhadap sesama. Didalam pembelajaran berbasis lingkungan, anak dapat mengamati perilaku sosial yang diamatinya. Dengan berpuasa, anak dapat memahami arti kepedulian terhadap sesamanya, merasakan penderitaan yang dialami oleh masyarakat yang tidak bisa makan secara teratur, dan melatih diri untuk selalu berhemat.

Berpuasa dimaknai sebagai suatu upaya menahan diri, berlatih untuk menahan diri terhadap sesuatu yang disukai atau diinginkan. Menunda kesenangan sesaat untuk dapat menikmatinya di saat yang lebih tepat. Langkah berpuasa ini bisa dilakukan dengan waktu yang bertahap durasinya sesuai dengan kemampuan anak.

Berdasarkan langkah-langkah diatas dan melalui pembiasaan yang telah dilakukan, maka secara bertahap dapat menanamkan nilai-nilai keimanan terhadap Allah. Semua kegiatan yang bersumber dari emosional anak, dapat dilakukan secara tindakan yang positif seiring dengan kecerdasan spiritual yang dimiliki. Kegiatan tersebut harus dilakukan sebagai bentuk rutinitas keseharian dan menjadikan implikasi terhadap kecerdasan emosional yang lainya. Sehingga kontrol dari kecerdasan emosional tersebut berdasarkan kecerdasan spiritual yang telah dimilikinya. Perilaku yang dilakukan bukan semata-mata atas dasar pengetahuan dan pengalaman saja. Akan tetapi semua perilaku berdasarkan nilai-nilai ketentuan dari apa yang diyakini dan diimani. Oleh sebab itu ESQ harus ditanamkan sejak dini sebagai bentuk penyeimbang didalam kehidupan.

\section{SIMPULAN}

Berdasarkan pembahasan hasil temuan dalam penelitian ini, diperoleh kesimpulan bahwa Ary Ginanjar Agustian memiliki perspektif bahwa metode ESQ Way 165: (a) berdasarkan pada nilai-nilai Ikhsan, Iman, dan Islam; (b) memiliki tahap penerapan berupa penjernihan emosi, pembangunan mental, ketangguhan pribadi, dan ketangguhan sosial, dan (c) memiliki tahap untuk pengembangan kecerdasan emosi dan spiritual pada anak berupa: Mission Statement, Character Building, dan Self Controling. Dengan demikian, metode ESQ Way 165 ini dapat direkomendasikan bagi para orangtua dan guru sebagai alternatif dalam mengembangkan kecerdasan emosi dan spiritual anak. Harapannya, mereka akan memiliki keterampilan dalam berpikir, memilih, dan memutuskan segala sesuatu dengan tepat dan berdasarkan nilai-nilai Ikhsan, Iman, dan Islam.

\section{DAFTAR PUSTAKA}

Arfiani, Y. (2014). Peran Komunikasi Orangtua Anak, Kecerdasan Emosi, Kecerdasan Spiritual, terhadap Perilaku Bullying (PhD Thesis). Universitas Muhammadiyah Surakarta.

Ginanjar, A. (2007). Rahasia Sukses Membangun Kecerdasan Emosi dan Spiritual: ESQ. Jakarta: Arga.

Goleman, D. (2000). Kecerdasan emosional. Gramedia Pustaka Utama.

Hariastuti, R. T., \& Saman, A. (2007). Mengembangkan Kecerdasan Emosional Anak. Jurnal Pendidikan Dasar, 8(1). 
Komarudin Hidaya. (2003). Mengembangkan Kecerdasan Spiritual Anak, dalam Buletin PAUD. Jakarta: Direktorat Pendidikan Anak Usia Dini, Depdiknas.

Liputan6.com (2017). Berita Harian Kenakalan Remaja - Kumpulan Berita Kenakalan Remaja Terbaru Hari Ini. Diambil 31 Maret 2018, dari http://www.liputan6.com/tag/kenakala n-remaja

Luthfiyani, A. K., Herawati, N. I., \& Rohayati, T. (2016). Pengaruh Metode Hypnoteaching terhadap Kecerdasan Emosional Anak Usia Dini. Jurnal PGPAUD Kampus Cibiru, 4(2).

Nindya, P. N., \& Margaretha, R. (2012). Hubungan Antara Kekerasan Emosional pada Anak terhadap Kecenderungan Kenakalan Remaja. Jurnal Psikologi Klinis dan Kesehatan Mental, 1(02), 1-9.

Rohmadheny, P. S. (2013). Pengaruh Penggunaan Metode Hypnoteaching Terhadap Emotional Intellegence Anak Usia 3-4 Tahun di Kelompok Bermain Tunas Harapan Tulungagung. Jurnal CARE (Children Advisory Research and Education), $1(1)$.

Setyowati, Y. (2013). Pola Komunikasi Keluarga dan Perkembangan Emosi Anak (Studi Kasus Penerapan Pola Komunikasi Keluarga dan Pengaruhnya terhadap Perkembangan Emosi Anak pada
Keluarga Jawa). Jurnal ILMU KOMUNIKASI, 2(1). https://doi.org/10.24002/jik.v2i1.253

Sindonews. (2017). Kenakalan Remaja. Diambil 31 Maret 2018, dari https://nasional.sindonews.com/read/1 258824/16/kenakalan-remaja1511113926

Suryani, W. (2014). Hubungan Pola Asuh Orang Tua terhadap Kecerdasan Emosional Anak Usia Dini di PAUD Saymara Kartasura Tahun Pelajaran 2014 (PhD Thesis). Universitas Muhammadiyah Surakarta.

Tikollah, M. R., Triyuwono, I., \& Ludigdo, U. (2006). Pengaruh Kecerdasan Intelektual, Kecerdasan Emosional, dan Kecerdasan Spiritual terhadap Sikap Etis Mahasiswa Akuntansi (Studi pada Perguruan Tinggi Negeri di Kota Makassar Provinsi Sulawesi Selatan). Simposium Nasional Akuntansi, 9, 23-26.

Trihandini, R. F. M. (2005). Analisis Pengaruh Kecerdasan Intelektual, Kecerdasan Emosi, dan Kecerdasan Spiritual Terhadap Kinerja Karyawan (Studi Kasus pada Hotel Horison Semarang) (PhD Thesis). Program Pascasarjana Universitas Diponegoro.

\section{BIOGRAFI SINGKAT PENULIS}

Ferdian Utama adalah dosen di IAIM NU Metro di Lampung Indonesia. 